\title{
Regression Analysis of Breaststroke Swim Performance from Physical, Physiological and Energy Parameters
}

\author{
Maulidin 1,a, Asmawi1,b, James Tangkudung1,c \\ ${ }^{1}$ Department of Sport Education, Universitas Negeri Jakarta, Jakarta Timur, 13220, Indonesia \\ a maulidin@ikipmataram.ac.id \\ ${ }^{*}$ Corresponding Author
}

How to Cite : Maulidin, M., Asmawi, A., Tangkudung, J. (2019). Regression Analysis of Breaststroke Swim Performance from Physical, Physiological and Energy Parameters. International Journal for Educational and Vocational Studies, 1 (3), 201-207.

\section{ARTICLE HISTORY}

Received:12 May 2019

Revised: 23 June 2019

Accepted: 24 July 2019

\section{KEYWORDS}

Effect of Leg Muscle;

Motivation;

Energy Cost of Breaststroke Swim

\begin{abstract}
The purpose of this research was to determine the effect of leg muscle power, maximal oxygen, and achievement motivation on breaststroke swimming athlete. This research used a survey method to see the direct relationship between height variables, leg muscle power, maximal oxygen volume, achievement motivation on breaststroke swimming athletes. The sample used 42 people who were determined by purposive male swimmers aged $15-17$ years and had participated in the championship. Performed an all-out 50-m breaststroke swimming test in a 50-m pool. The data analysis technique uses path analysis. The results of the analysis of each variable have direct effects where: Body height has a positive direct effect on swimming skills $\left(R^{2}=0.308\right)$, leg muscle power has a positive direct effect on swimming skills $\left.\left(R^{2}=0.548\right), 3\right)$ the energy cost of oxygen has an effect positive direct to swimming skills of $\left(R^{2}=0.519\right)$, motivation has a positive direct effect on athlete swimming skills with $\left(R^{2}=\right.$ 0.419). Of the five-leg muscle power variables that have the greatest influence on breaststroke, swimming speed is $54.8 \%$ the remaining $45.2 \%$ is caused by other factors such as weather conditions, mental state, nutrition, recovery and health conditions of athletes.
\end{abstract}

This is an open access article under the CC-BY-SA license.

\section{INTRODUCTION}

The swimming sport is a measurable branch of sporto that the achievement of training results can be measured and predicted precisely determining the achievement of the game. Swimming skills are judged in general based on the time record obtained at a certain race distance, because swimming is a branch of sport which according to The Primary Mechanical Purpose of Skill (TMU) is categorized as "to move the body over a prescribe distance or without a time constraint, "or sports branch that moves the body from one point to another (Roger Eston., 2009), Mastery of skills in each sport is based on mastering basic skills. There are three systems that can represent the classification of motion skill that is: (a) environmental stability (b) whether or not the starting and ending points of the movement are clear, and (c) the intended movement speed (Yani Mulyani and Juliska Gracinia, 2007). In swimming, one of the factors that achieves athlete's achievements is anthropometry (body posture), specifically in sprint category. Certain anthropometric characteristics should be considered in analyzing the sear- ch for short-range swimming talent, including height, range of arms and lean body mass (Jürimäe et al., 2007; Strzala and Tyka, 2009). Physical development in children of one age has a significant difference in the proportion of body size, degree of development of the bone and muscle system, in sexual development, etc. (Lee, 2003). Understanding physical and anthropometric factors effectively can support the achievement of swimming prescriptions in relation to talent development (Mevaloo, S.F 2008).

In breaststroke movements, an athlete is more determined by muscle mass because the anatomy of their legs tend to be more stable and the structure of the body is heavy so it needs to absorb a lot of energy while moving from one place to another. The motor unit is the motor nerve plus muscle fibers that function as the basis of the skeletal muscle. (Guyton, 2006) in the breaststroke (BS) the kick is more important for the strength and efficiency of the energy released (Strzała et al., 2012). From the motoric nerve, all muscle fibers contract accordingly or not. If there is a lot of muscle fiber mass, then the 
contraction will be stronger, conversely if the mass of muscle fibers is a little then the contraction will be weak. If the muscle contracts up to $60 \%$ of its maximum capacity, the blood flow to the brain stops or stagnates, due to high intramuscular pressure. (Lumintuarso, 2013).

In swimming, there are three energy systems which play the ATP-PC energy system for explosive movements, anaerobic glycolysis (lactic acid) energy systems for high-intensity swimming with short distances and aerobic glycolysis energy systems for long-distance swimming (Ferran et al., 2010). In breaststroke sprints a distance of 50-100 meters requires contraction of large muscles. Contraction of large muscles serves to produce high energy, which is more than 200 mLO2.kg-1.min -1. Many large muscles contain type II muscle fibers (fast twitch fibers) with high glycolytic energy so that the energy produced is greater. Deposits of ATP and phosphocreatine decrease rapidly and the glycolysis process will soon occur to maintain energy production.

\section{LITERATURE REVIEW}

Anthropometric factors are congenital (genetic) factors that are very difficult to change, such as height, arm length and so on, so that the development of achievements cannot be separated from the anthropometric characteristics of the athlete concerned. Anthropometry is the science of measuring problems with weight, size, and proportion of the human body and its parts (proportion of the human body and its parts). (Tangkudung, 2012). The athlete's height when facedown is the length of the entire body dividing the length of the pool and the distance that will be traveled. The longer the body divides; the pool will become imaginary pieces that are less than the body that is not long. Understanding physical and anthropometric factors that support achievement in swimming sports is very important for talent development and targeting training programs effectively (Mevaloo, 2008).

In swimming breaststroke, the role of the legs is very important to push the body in the water so that it travels quickly. Maglischo (1993) stated that feet play a more dominant role than arm movements in breaststroke training. Maglischo states that 60 percent of chest force movements are leg movements. This means $60 \%$ of the power is produced by the foot and $40 \%$ by the arm. Maglischo further said that in several thousand meters of total training given to breaststroke swimmers, $75-80 \%$ of training program material focused on the feet, both on endurance or on speed (Maglischo, 1993). Counsilman, head swimmer at UCLA United States, said that to increase explosive power and muscle endurance, swimmers must use weight training, because by doing weight training, breaststroke swimmers will gain strength, especially from the legs (Counsilman, 1977). To get fast and repetitive movements the legs must have a strong power. Power is a combination of strength and speed. Based on its energy system, breaststroke is a fast-motion sport which is dominated by elements of physical conditions called power (Sukadianto, 2011). Another opinion is that power is the muscular power of one's ability to use the maximum leg muscle power that is deployed in the shortest possible time, in this case it can be stated that muscle explosive power $=$ force $\mathrm{x}$ speed (velocity). Power is related to style and time, (David S., 2015) Power in swimming techniques is very important because strength and speed are the driving forces for each activity and are a prerequisite for improving achievement (Aribinuko T., 2000).

In breaststroke sprints a distance of 50-100 meters requires contraction of large muscles. Contraction of large muscles serves to produce high energy, which is more than 200 mLO2.kg-1.min-1. Many large muscles contain type II muscle fibers (fast twitch fibers) with high glycolytic energy so that the energy produced is greater. In sprint swimming 50-100 meters there will be an increase in lactic acid which is quite high, 12-14 mmol. What causes acidosis (Rodriguez et al., 2010). The energy needed for breaststroke is greater because in the breaststroke pool there must be coordination between the movement of the arms and legs to allow the body to move while lifting the upper body moving above the water surface. greater energy is needed in breaststroke swimming because breaststroke is a swimming style that in the cycle of movement, the body is against the direction of swimming so that more energy is needed to fight resistance in water at any increase in swimming speed (David Haller, 2007).

In achieving one's psychological factors achievement is also very influential As stated by Sudibyo (2001), personality is not easily seen and known as personality is a complex unit of soul; personality will be reflected in ideals, characters, attitudes, attributes and actions. Thus, the psychological symptoms shown by the athlete's mental and personality can influence their performance as translated by their motivation and attitudes. Meanwhile, Chaplin (2001) stated that personality is an intervening variable causing certain factors in an organism, which produce, manage, maintain, and channel behavior towards one goal. In the personality of each individual has different motivations that will encourage things to do. James Tangkudung (2012) says that motivation is an impulse that arises in a person, conscious or unconscious to do an action with a specific purpose. A person's motivation will affect the level of performance when the athlete starts competing because of that, motivation is the desire or desire contained in the individual for a particular activity. It is the desire to be the main factor that determines the individual, whether he will act or not. And that motivation itself cannot be observed by others but motivation will usually be reflected in one's behavior.

\section{METHODS}

The method of this research is path analysis by looking at causality between variables of leg muscle power, anaerobic and motivation to perform against swimming 
speed. The sample used 42 people who were determined by purposive male swimmers aged 15-17 years and had participated in the championship PORPROV NTB. In order for a representative sample and the obtained value to be regenerated to the existing population, prior observations of the possibilities that can influence the results of the study are carried out.

\section{Instrument}

Height (cm) and body mass (kg) were assessed using SECA stadiometres and weighing scales $\pm 0.1 \mathrm{~cm}$ and 0.1 $\mathrm{kg}$; leg muscle power was assessed using digital JUMP-DF, the sample was given the opportunity to jump twice and the best value was taken and then configured with the formula ( $\left.P=\frac{m \cdot g \cdot d}{t}=j o u l e / s e c o n d\right)$, Cardiao endurance was assessed by swimming beep test, motivation was assessed using a motivational questionnaire that had been validated by experts and was suitable for use.

\section{Statistical Analysis}

Statistical analysis of data normality using the Kolmogorov-Smirnov test, and the Test of Homogeneity of Variances, the linearity test and the significance of the

\begin{tabular}{|c|c|c|c|c|c|c|c|}
\hline \multirow{2}{*}{ Variabel } & \multirow{2}{*}{$\begin{array}{l}\mathrm{N} \\
\text { Statistic }\end{array}$} & \multirow{2}{*}{$\begin{array}{c}\text { Min } \\
\text { Statistic }\end{array}$} & \multirow{2}{*}{$\frac{\text { Max }}{\text { Statistic }}$} & \multicolumn{2}{|c|}{ Mean } & \multirow{2}{*}{$\begin{array}{c}\text { Std. Deviasi } \\
\text { Statistic }\end{array}$} & \multirow{2}{*}{$\begin{array}{l}\text { Variance } \\
\text { Statistic }\end{array}$} \\
\hline & & & & Statistic & Std. Eror & & \\
\hline Leg muscles power & 40 & 38 & 67 & 51.2 & 1.442 & 9.125 & 83.269 \\
\hline Energy cost & 40 & 36 & 46 & 55.2 & 0.660 & 4.175 & 17.435 \\
\hline Achievement Motivation & 40 & 42 & 89 & 65.4 & 2.106 & 13.320 & 77.420 \\
\hline Valid N (listwise) & 40 & 33 & 42 & 37.7 & 0.402 & 2.542 & 6.461 \\
\hline
\end{tabular}

\section{Linearity Test and Significance of Regression Equation}

Test results from the linearity of the regression Leg muscles power equations obtained from the ANOVA where the line of deviation linearity is measured $\mathrm{F}_{\text {count }}=$ 0.499 , with $\mathrm{p}$-volue $=0.925>0.05$. This means that Ho is accepted or the regression equation is linear or in the form of a straight line. While the results of the regression line equation test obtained from regression rows, namely $\mathrm{F}_{\text {count }}$ $(\mathrm{b} / \mathrm{a})=41.927$, and $\mathrm{p}$-volue $=0.013<0.05$ Ho is rejected . Thus, the regression Leg muscles power of swimming speed is significant, The test results of the regression energy cost equation linearity obtained from the ANOVA where the line of deviation linearity is measured $\mathrm{F}_{\text {count }}=$ 0.645 , with $\mathrm{p}$-volue $=0.763>0.05$. This means that Ho is accepted or the energy cost regression equation is linear or in the form of a straight line. While the significant test results from the results of the test results of the significance of the regression line equations obtained from regression rows, $\mathrm{F}_{\text {count }}(\mathrm{b} / \mathrm{a})=54.729$, and $\mathrm{p}$-volue $=0.039$ $<0.05$. The regression energy cost of swimming speed is regression equation using the $\mathrm{F}$ ANAVA test criteria if (F-count $>$ F-table) then, the linear regression equation and $\mathrm{A}$ p-value $\leq .05$ was considered to be statistically significant. Furthermore, the t-test is used to determine the direct effect between variables. Data analysis was aided by the SPSS version 22.0 program.

\section{RESULTS AND DISCUSSION}

\section{Results}

Mean ( \pm SD) $50-m$ performance time was $55.6 \pm 9.1 \mathrm{~s}$. Descriptive statistics for anthropometrical physiological and psychology parameters and thei relationship with 50breastsrroke performance time presented in Table 1 . with body height,leg muscel power, energy cost and Achievement Motivation.

\section{Table 1.}

Body haight, leg muscel power, energy cos and psychology and their correlate with $50-\mathrm{m}$ breastrstroke swimming performance in adolescent swimmers in =40). Data are means ( \pm standard deviations, SD), minimal and maximal, and partial correlation coefficients variable. significant, The test results of the regression achievement motivation equation is linear or in the form of a straight line. While the significant test results from the results of the test results of the significance of the regression line equations obtained from regression rows, $\mathrm{F}_{\text {count }}(\mathrm{b} / \mathrm{a})=$ 6.417, and $p$-volue $=0.016<0.05$ The regression achievement motivation of swimming speed is significant.

Table 2.

Backward stepwise linear regression analysis to assess potential relationships with swimming performance and evaluate parameter groups (Leg muscle power, energy cost and achievement motivation). 


\begin{tabular}{|c|c|c|c|c|c|c|}
\hline Variable & & $\begin{array}{l}\text { Sum of } \\
\text { Squares }\end{array}$ & df & $\begin{array}{l}\text { Mean } \\
\text { Square }\end{array}$ & $\mathrm{F}$ & Sig \\
\hline Leg muscle power to swimming speed & Deviation frpm Linearity Regression & 68.976 & 17 & 5.953 & $\begin{array}{l}499 \\
41.927\end{array}$ & $\begin{array}{l}.925 \\
.013^{a}\end{array}$ \\
\hline Energi cost to swimming speed & Deviation frpm Linearity Regression & 46.273 & 10 & 4.627 & $\begin{array}{l}645 \\
54.729\end{array}$ & $\begin{array}{l}.763 \\
.039 \mathrm{a}\end{array}$ \\
\hline $\begin{array}{l}\text { Achievement Motivation to swimming } \\
\text { speed }\end{array}$ & Deviation frpm Linearity Regression & 91.240 & 17 & 5.367 & $\begin{array}{l}906 \\
6.417\end{array}$ & $\begin{array}{l}.577 \\
.016^{\mathrm{a}}\end{array}$ \\
\hline
\end{tabular}

\section{Regression Coefficient Test between variables}

On Table 03 above, it has been explained That power of leg muscles has a positive direct effect on the speed of swimming 50 meters breaststroke athletes. This is seen from the results of the regression coefficient calculation above, obtained $t_{\text {count }}=5.388 p=013$, leg muscle power has a positive effect on the swimming speed of 50 meters breaststroke athlete's Accepted. That the energy cost has a positive direct effect on the speed of swimming 50 meters breaststroke speed. This is seen from the results of the regression coefficient calculation above, obtained value $t_{\text {count }}=4.546$ and $p=039$, meaning. From the results of these calculations has a positive effect on the swimming speed of 50 meters of the breaststroke athletes. Maximum oxygen has a positive direct effect on the swimming speed of 50 meters of the breaststroke athlete's. That the achievement motivation has a positive direct effect on breaststroke speed 50 meters. This is seen from the results of the regression coefficient calculation above, obtained $t_{\text {count }}=2.533$ and $p=016$ meaning. From the results of these calculations has a positive effect on the breaststroke speed in Mataram athletes. Motivation for achievement has a direct positive effect on the swimming speed of the 50 meter of breaststroke athletes.

Table 2.

Height regression coefficient test for swimming speed

\begin{tabular}{|c|c|c|c|c|c|}
\hline \multirow{2}{*}{ Variable } & \multicolumn{2}{|c|}{ Unstandardized Coefficients } & \multirow{2}{*}{$\begin{array}{c}\text { Standardized Coefficients } \\
\text { Beta }\end{array}$} & \multirow{2}{*}{$\mathrm{t}_{\text {count }}$} & \multirow{2}{*}{$\mathrm{Sig}$} \\
\hline & $B$ & Std. Error & & & \\
\hline $\begin{array}{l}\text { Leg muscles power with } \\
\text { Swimming Speed }\end{array}$ & 461 & 044 & 220 & 5.388 & 013 \\
\hline $\begin{array}{l}\text { Energy cost with } \\
\text { swimming speed }\end{array}$ & 383 & 098 & 737 & 4.546 & 039 \\
\hline Achievement Motivation with swimming speed & 473 & 029 & 380 & 2.533 & 016 \\
\hline
\end{tabular}

Multiple linear regression analysis demonstrated leg muscel power $\left(R^{2}=0.548 ; \mathrm{p}<0,05\right)$, This means that $54.8 \%$ has a direct influence on the swimming breaststroke speed of 50 meters in Mataram athletes and the remaining $45.2 \%$ is caused by other factors, energy cost of oxygen $\left(R^{2}=0.519 ; \mathrm{p}, 0,05\right)$ This means that $49,1 \%$ has a direct influence on the swimming breaststroke speed of 50 meters in Mataram athletes and the remaining $49,1 \%$ is caused by other factors, Achievement Motivation $\left(R^{2}=\right.$
$0.419 ; \mathrm{p}, 0.05)$. This means that $41,9 \%$ has a direct influence on the swimming breaststroke speed of 50 meters in Mataram athletes and the remaining $59,1 \%$ is caused by other factors.

Table 3.

Backward stepwise linear regression analysis to assess potential relationships with swimming performance and evaluate parameter groups (Anthropometrics, leg muscle power, energy cost and achievement motivation)

\begin{tabular}{|c|c|c|c|c|}
\hline Variabel & $\mathrm{R}^{2}$ & Adjusted R & $t_{\text {count }}$ & $p$ \\
\hline Leg muscle power & .548 & .023 & 5.388 & 013 \\
\hline Energi cost & .519 & 667 & 3.854 & 039 \\
\hline Motivation & .419 & .122 & 2.533 & 016 \\
\hline
\end{tabular}

\section{Discussion}

Based on the results of hypothesis testing, it turns out that the depth of the proposed hypothesis shows positive correlated results. The description of each hypothesis can be explained as follows:

\section{The Effect of Leg Muscle Power on Swimming Speed of} 50 Meters Breaststroke for Mataram Athletes.

Swimming is one of the strenuous sports that requires a good level of physical condition, because it will bring the body from the burden that comes from water quickly, in 
the swimming 50 breaststroke number 50 meters on average 30 seconds (best time Surabaya National Championship, 24.27 seconds) so that explosive power is needed. The movement of kicking or kicking in the chest style produces more encouragement and forward movement compared to other styles. In swimming sports, speed is needed. Because the distance traveled is short, one of the supporting factors to quickly finish is the explosive power of the leg muscles. Muscle explosive power that will be needed to return to the sport as well as breaststroke, the most dominant muscle explosive power used is the explosive power of the leg muscles. Therefore, increased muscle strength can produce a higher maximum force at swimming speeds, especially in sprint range (Strzala \& Tyka, 2009; Morouço et al., 2011a).

Muscular power is the ability of a person to use the maximum power that is deployed in the shortest amount of time. So the explosive power of the leg muscles is the ability of the leg muscles that are deployed in a short time (Harsoso, 2015). Breaststroke is a very specific swimming style when viewed from foot movements and arm movements, either by increasing the swimmer's speed or maintaining the body's position to remain as even as possible with water or water flow. According to Bunn (1972), the breaststroke swimming movement was the only movement that was very calm. In addition, Hogg (1982) said that the foot is the main source of attractive breaststroke that the level of strength or pull on the dominant breaststroke is produced by the pull of the foot. Richard (2005) said that breaststroke is a calm swimming style, because the attraction to move forward in glide is the result of a series of movements between the legs and arms with the right coordination and time.

\section{The Effect of Maximal Oxygen Volume (VO2Max) on the} Swimming Speed of 50 Meters Breaststroke for

\section{Mataram Athletes}

Swimming is a sport that is carried out in the water by moving the limbs repeatedly, in the renegotiation of the breaststroke style by lifting the head above the surface of the water to take oxygen (O2) at each pulling the arm into the water. The head is re-inserted into the water when the arm is doing recovery so it requires a lot of energy. Greater energy is needed in the breaststroke pool, the body opposes the direction of swimming so that more energy is needed to fight resistance in the water at any increase in swimming speed (Caputo, R., Ogita, F., Tabata, 2006). Basic energy production for body metabolism and myocardium is glucose and lactic acid. Extraction and benefits of lactic acid are determined by cardiovascular function, while glucose uptake is not affected by blood circulation, but by insulin movement. Taking lactic acid looks higher in the untrained group, but in the group that is trained lactic acid is used to increase metabolic energy. The fast component describes the amount of energy needed to restore ATP and phosphocreatine reserves in the muscle. The synthesis of ATP and phosphocreatine $70 \%$ occurs in the first 30 seconds of the recovery phase and the synthesis of ATP and phosphocreatine $100 \%$ occurs in the $3^{\text {rd }}$ minute of the recovery phase (Fernandesand (2012). A respiratory snorkel and valve system with low hydrodynamic resistance was used to collect breathing air samples (Keskinen et al., 2003; Rod- riguez et al., 2008; Toussaint et al., 1987) and was connected to a telemetric portable breath-by-breath gas analyzer (Metamax-3B, Cortex, Leipzig, Germany) (Aspenes et al., 2009). Values were averaged for 10-s periods. The respiratory device, connected to a portable gas analyzer of similar technical characteristics (K4 b , Cosmed, Italy) has demonstrated good validity and accuracy (Keskinen et al., 2003; Rodriguez et al., 2008) and has been used in recent published works (Barbosa et al., 2005a; Rodriguez et al., 2003). Swim performance was assessed from the time spend in seconds.

The swimmers were familiarized with the snorkel by letting them swim 100-m at moderate speed with the breathing apparatus preceding the maximal trial. Energy required for swimming breaststroke is greater than freestyle swimming so that will increase the amount of oxygen consumed after doing physical activity so that it is less effective for restoring ATP and phosphocreatin reserves. The body's ability to use oxygen optimally (VO2 Max) is an efficient way to provide energy, for 50-m breaststroke swimmers to be able to excel. will increase the need for oxygen to meet energy needs, but the body has a limited ability to take oxygen so that everyone has a different maximum ability limit. The work intensity is usually described by the percentage (\%) VO2 max, at a work level of less than 60-65\% VO2 max. Carbohydrate and glue donations It is balanced and at the level of work above $65 \%$ the main energy source comes from carbohydrates.

\section{The Effect of Motivation on Swimming Speed 50 Meters Breaststroke for Mataram Swimming Athletes.}

Motivation is an impulse that exists in a person with respect to achievement, motivation can be divided into two parts: internal motivation is motivation that arises from within the individual itself such as getting praise from the people and motivations that come from outside such as gifts, certificates and coaching money that will be obtained so that athletes become enthusiastic to get an achievement. The research of achievement motivation have gone in several directions. One group of researchers was concerned with the connection of this motivational disposition with some other psychological constructs such as locus of control (Popadić, 1986, ac-cording to Franceško and Mihić, 2002), with some of the stimulation factors for the development of the motives of achievement, such as obtaining feedback (McClelland, 1989, according to Franceško and Mihić, 2002) or with other cognitive motivational dispositions (McClelland, 1989, according to Franceško and Mihić, 2002) such as the 
affiliate motive and the power motive (Sokolowski, Schmalt, Langens and Puca, 2000). However, in most research the motive for achievement was observed as a factor of success in some activity (Pajares et al., 2000; Zimmerman, 2000; Puca and Schmalt, 2001). Achievement motivation is defined as an effort to increase or carry out personal skills as high as possible in all activities and a measure of excellence is used as a comparison, even though in an effort to carry out these activities there are two possibilities namely failure or success. He further explained that achievement motivation is a motive that encourages individuals to achieve success and aims to succeed in competition with several standards of excellence. The measure of excellence is used for the standard of achievement of self-achieved achievement before and is feasible as in a competition.

\section{CONCLUSION}

Based on the results of testing hypotheses and discussing the results of the research, it can be concluded as follows:

The power of leg muscles give a positive direct influence on the swimming speed of 50 meters of Mataram athlete's breaststroke style in 2018, which is usually seen from the results of determination coefficients from the table. $\mathrm{R}$ Square is obtained at 0.548 , which means that $54.8 \%$ of the total limb muscle power of Mataram swimming athletes. This means that $54.8 \%$ have an influence on the swimming speed of 50 meters in the breaststroke of Mataram athletes and the remaining $45.2 \%$ is due to other factors.

Maximum oxygen volume (VO2Max) has a positive direct effect on the swimming speed of 50 meters of the Mataram athlete's breast force in 2018. Where it is usually seen from the results of determination coefficient from the table, $\mathrm{R}$ Square is obtained 0.519 which means that $51.9 \%$ of the maximum oxygen volume of Mataram swimming athletes. This means that $51.9 \%$ have an influence on the swimming speed of 50 meters in the Mataram athlete's breaststroke and the remaining $48.1 \%$ is due to other factors.

Motivation for achievement has a direct positive effect on the swimming speed of the 50 meter breaststroke of Mataram athletes in 2018. Where it is commonly seen from the results of the determination coefficient of the table, $\mathrm{R}$ Square is obtained by 0.419 , which means that $41,9 \%$ of the maximum oxygen volume of Mataram swimming athletes. This means that $41,9 \%$ have an influence on the swimming speed of 50 meters of Mataram athletes breaststroke and the remaining $59,1 \%$ is caused by other factors.

\section{REFERENCES}

Achmad S.,H. \& Pringgo M. (2014) Teaching Styles and Motivation in Learning Breast Stroke in Swimming. Published by Canadian Center of Science and
Education 10, 1-6 Universitas Negeri Jakarta, Jakarta, Indonesia doi:10.5539/ass.v10n5p2

Almaz F. M., Afanasiy A. S. (2019) Correlation of Physical Development Indicators with Speed-Strength Performance in 11-12-Year-Old Boys. International Journal of Instruction 12 (1) 269-282

Aribinuko T. (2000). Teknik Dasar Renang. Jakarta: Intan Pariwara

Barbosa, T.M., Fernandes, R., Keskinen, K.L., Colaco, P., Cardoso, C., Silva, J. and Vilas-Boas, J.P. (2006) Evaluation of the energy expenditure in competitive swimming strokes. International Journal of Sports Medicine 27, 894-899.

Carew, K. R., Piiper, J., Roos, A. (2003) Relationship of Lactic acid Production, Velocity and Metabolism in Competitive Swimming. Journal of Applied Physiology 215: pp 522-525

Carew, K. R., Piiper, J., Roos, A. (20030 Relationship of Lactic acid Production, Velocity and Metabolism in Competitive Swimming. Journal of Sports Science and Medicine Journal of Applied Physiology 215: pp 522-525,

Daisy, B., Laura, G., Samuel W., Oxford, A. M., Nevill. (2015) The Association between Anthropometric Variables, Functional Movement Screen Scores and $100 \mathrm{~m}$ Freestyle Swimming Performance in Youth Swimmers. Centre for Applied Biological and Exercise Sciences, Coventry University. Sports, 3, 1-11; doi:10.3390/sports3010001

David H. (2007) Renang Tingkat Mahir. Jakarta: Raja Grafindo Persada

Duda, J. L. (1996). Maximizing motivation in sport and physical education among children and adolescents: the case for greater task involvement. Quest, 48, 290-302.

Duda, J. L., \& Balaguer, I. (2007). Coach-created motivational climate. Social psychology in sport. Jowett S., Lavallee D., editors. Champaign, IL: Human Kinetics; 117-13.

Duda, J. L., \& Nicholls, J. G. (1992). Dimensions of achievement motivation in schoolwork and sport. Journal of Educational Psychology, 84, 290-299.

Education on the Intention to Practice Physical Activity or Sport. European Journal of Sport Science, 1(4), 1-12.

Evelin L, Jaak J, Priitpurge. (2010) Physiological, biomeanikal and antropometri predictor of sprin swimming performance in adolecent swimmer. Journal of Sports Science and Medicine Department of Sport Science and Kinesiology, University of Salzburg, Austria, CD-Laboratory "Biomechanics inSkiing", 9, 398-404

Evelin Lätt., Jürimäe, J., Haljaste, K., Cicchella, A., Lätt, E., Purge, P., Leppik, A. and Jürimäe, T. (2007) Analysis of swimming performance from physical, physiological and biomechanical parameters inyoung 
swimmers. Journal of Sports Science and Medicine Pediatric Exercise Science 19, 70-81.(Journal of Sports Science and Medicine 9, 398-404)

Fernandesand (2012). Timetoexhaustionatthe VO2max velocity in swimming: a review," Journal of Human Kinetics. 32, pp.121-134,.

Ferran, C. B., Brand, M. D., Nic holls, D. G. (2010) Aerobic and Anaerobic Energy Expenditure. Exercise Sport Journal 66: pp 239-242

Ferran, C. B., Brand, M. D., Nic holls, D. G. (2010). Aerobic and A naerobic Energy Expenditure. Exercise Sport Journal 66 : pp 239-242

Kadir. 2015. Statistik Terapan (Konsep, Contoh dan Analisis Data Dengan Program SPSS/Lisrel dalam Penelitian). Jakarta; Rajawali Pers

Lumintuarso, R., (2013) Teori Kepelatihan Olahraga. Jakarta. Lankor

Mevaloo, S.F. ; Shahpar, F.M. (2008) Talent identification programmes. In Proceedings of the 17th FINA World Sport "Medicine Congress. Enhancing Performance: The Healthy Aquatic Athlete", Manchester, UK, 7-8

Pendro, G. M., Daniel, A. M., Nuno, M. A., Jose, A. P., Mario. C. M. (2014). Effects of dry-land strength training on swimming performance. JOURNAL OF HUMAN SPORT \& EXERCISE. University of Beira Interior, Department of Sport Sciences, UBI, Covilhã, Portugal . 2, pp. 553-559, doi:10.4100/jhse.2012.72.18

Rodriquez, C. E., Binzoni, T.,Ferretti, G. (2010). Aerobic and Anaerobic Metabolism in Swimming. Journal of Applied Physiology 19 : pp 20-23:

Rodriquez, C. E., Binzoni, T.,Ferretti, G. (2010). Aerobic and Anaerobic Metabolism in Swimming. Journal of Applied Physiology 19: pp 20-23:

Roger .W, (2008) National Strength and Conditioning Association, Canada: Human Kinetics

Roger, E., Thomas R. (2009) Kinanthropometry end exercise physiologi raboratory manual: test, procedur, and data 3 edition. New York: Tailor \& Francis

Saharuddin, I. (2014) The Influence of the Forms of Exercise and Leg Muscle Power towards Breast Stroke Skills. Published by Canadian Center of Science and Education. 5, 104-108 doi:10.5539/ass.v10n5p104

Stella R., Olga K., Evangelos B., Dimitrios., George M. (2009) Effect of Dance Aerobic Programs on Intrinsic Motivation and Perceived Task Climate in Secondary School Students. International Journal of Instruction. pp. 641-654. e-ISSN: 1308-1470 • www.e-iji.net

Strzala, M. and Tyka, A.. (2009). Physical endurance, somatic indices and swimming technique parameters as determinants of breast stroke swimming speed at short distances in young swimmers. International Jurnal Sport Siece Medicina Sportiva 13, 99-10:

Tangkudung, J. (2013) Sistem Energi dan asam Laktat Untuk Mningkatkan Prestasi Atlet. Jakarta:
Pascasarjana Universitas Negeri Jakarta,

Tangkudung, J. dan Puspitorini. (2012) Kepelatihan Olahraga "Pembinaan Prestasi Olahraga. Jakarta: Cerdas Jaya 